\title{
Expression of the crucifer-infecting TMV-Cg movement protein in tobacco plants complements in trans a TMV-U1 trafficking-deficient mutant
}

\author{
FELIPE DÍAZ-GRIFFERO ${ }^{1, *}$, CARMEN ESPINOZA CANCINO ${ }^{2, *}$, \\ CONSUELO MEDINA ARÉVALO ${ }^{2}$ and PATRICIO ARCE-JOHNSON ${ }^{2}$
}

\author{
${ }^{1}$ Department of Pathology, Harvard Medical School, Boston, MA, USA. \\ ${ }^{2}$ Department of Molecular Genetics and Microbiology, Faculty of Biological Science, Pontificia Universidad \\ Católica de Chile, Santiago, Chile. \\ * Both authors contributed equally to this work.
}

\begin{abstract}
Tobamovirus movement proteins play a determinant role in the establishment of infections in plants, allowing the local movement of viral RNA genome through plasmodesmatas. We expressed the movement protein (MP) of the crucifer- and garlic-infecting Tobacco Mosaic Virus strain Cg (TMV-Cg) in both resistant Xanthi NN and sensitive Xanthi nn Nicotiana tabacum plants. MP-Cg function was assayed by inoculating transgenic plants with a trafficking-deficient mutant of TMV strain U1. Following infection, local necrotic lesions were developed in resistant transgenic plants, and a systemic infection was produced in sensitive tobaccos. Thus, movement function of the mutant virus was complemented in trans by MP-Cg expressed in transgenic plants, causing the same symptoms as wild-type strain. We demonstrated that the function of MP-U1 could be replaced efficiently by $\mathrm{MP}-\mathrm{Cg}$, even though these proteins share only $36 \%$ of identity. Similar hydrophobic patterns of MP-Cg and MP-U1 suggests structure and function conservations of both proteins. This work is an example of how two tobamoviruses differing in their host range help to understand viral movement mechanism during the infection.
\end{abstract}

Key terms: movement protein, crucifer-infecting tobamovirus, viral complementation.

\section{INTRODUCTION}

Infection of a susceptible host by a plant virus requires local trafficking from the site of pathogen entry into the vascular system, allowing viral spread through the entire plant. The long-distance movement of plant viruses through vascular tissue has been described as a passive process that moves with the phloematic flow of photoassimilates (Leisner and Howell, 1993). In contrast, local or cell-to-cell movement during infection is an active process that occurs through specialized plasma-membrane cytoplasmic channels known as plasmodesmatas (PDs). These intercellular organelles confer to plant cells several different functions, including coordination of gene expression, nutrient distribution, pathogen response, and RNA transport (Ghoshroy et al., 1997; Haywood et al., 2002; Zambryski, 2004). The PDs present a size-exclusion limit of $2.5 \mathrm{~nm}$, restricting simple diffusion of large molecules, such as viral genomes or viral proteins. For this reason, plant viruses encode movement proteins (MP), which are essential for local movement of the viral genome through plasmodesmatas, allowing the establishment of a successful infection (Carrington et al., 1996).

Tobacco Mosaic Virus strain U1 (TMVU1, Accession number J02415) belongs to the solanaceous-infecting subgroup of

Corresponding author: Patricio Arce-Johnson, Alameda 340, Laboratory of Biochemistry, Department of Molecular Genetics and Microbiology, Faculty of Biological Science, Pontificia Universidad Católica de Chile, Santiago, Chile, Tel.: (56-2) 686-2897, Fax: (56-2) 222-5515, E-mail: parce@bio.puc.cl 
tobamovirus and has been used as a study model of plant viral infection. Its positivesense RNA genome of 6395 nucleotides contains four open reading frames. The 5' open reading frame encodes a $126-\mathrm{kDa}$ protein that is terminated by an amber stop codon and a read-through this stop codon results in $183-\mathrm{kDa}$ protein. Both proteins contain methyl-transferase and helicase domains, but only the $183-\mathrm{kDa}$ protein presents a polymerase activity (Goregaoker et al., 2003). 126-kDa and 183-kDa proteins form a complex that is essential for viral replication and subgenomic messenger RNAs transcription. A $30-\mathrm{kDa}$ movement protein (MP) and a $17.5-\mathrm{kDa}$ coat protein (CP) are translated from independent mRNAs derived from minus-strand subgenomic promoters (Beachy and Zaitlin, 1977). The crucifer-infecting tobamovirus TMV-Cg (Chinese Rape Mosaic, Oilseed Rape Mosaic, or Youcai Mosaic Virus, Accession number D38444) also belongs to the tobamovirus genus (Yamanaka et al., 1998). TMV-Cg genome has 6303 nucleotides and encodes for the four characteristic proteins of these viruses. These proteins are arranged in a similar organization compared to other tobamoviruses and exhibit the same expression strategy. The movement protein of TMV-U1 (MP-U1) is one of the best-characterized movement proteins. This 30- kDa protein has 268 amino acids (Deom et al., 1987), whereas TMV-Cg movement protein (MP-Cg) corresponds to a 265 amino acid protein and has been less studied.

The movement protein is produced early after infection (Watanabe et al., 1984) and facilitates the cell-to-cell spread of viral ribonucleoprotein complexes through PDs (Carrington et al., 1996; Kawakami et al., 2004). Experimental approaches using either MP-expressing transgenic plants or infected tissues have been used to highlight MPs biological features. MP binds to nucleic acids in vitro in a cooperative manner and without sequence specificity (Citovsky et al., 1990). This interaction forms an extended MP-viral RNA complex that can move through the plasmodesmatal channel (Citovsky et al., 1992). Previous studies have shown that MP is present in cell wall-enriched protein fractions, accumulates in secondary PD, and is able to induce a 10- to 15-fold increase in its sizeexclusion limit (Wolf, 1989). MP becomes phosphorylated within host cells (Citovsky et al., 1993; Haley et al., 1995; Watanabe et al., 1992). This post-translational modification of MP could be involved in viral infectivity and have a regulatory role on MP ability to increase the size-exclusion limit of PDs (Karger et al., 2003; Kawakami et al., 2004; Lee and Lucas, 2001; Waigmann et al., 2000). MP interaction with cytoskeletal elements, including microtubules and actin microfilaments also has been described (Heinlein et al., 1995; Kawakami et al., 2004).

Tobamovirus movement proteins have been exchanged between viruses of the same genus without affecting viral-host interaction (Morozov et al., 1997; Nejidat et al., 1991; Padgett and Beachy, 1993). Furthermore, in some cases MPs can be exchanged between unrelated viruses (Briddon and Markham, 2001; Cooper et al., 1996; Hacker and Fowler, 2000; Morozov et al., 1997; Tamai et al., 2003). This evidence suggests that the MP of different plant viruses have evolved towards a similar function: the transport of viral genome through PDs.

Cell-to-cell movement is fundamental to the infective processes, and it requires movement proteins (Ruiz-Medrano et al., 2004). In previous works, we have compared the movement of two tobamoviruses, TMV-U1 and $\mathrm{TMV}-\mathrm{Cg}$ in tobacco and Arabidopsis thaliana plants (Arce-Johnson et al., 2003; Pereda et al., 2000). These two viruses differ in their host range and in their induced symptoms in sensitive tobacco plants. While TMV-U1infected plants show the characteristic systemic mosaic, TMV-Cg induces local lesions on inoculated leaves similar to a hypersensitive response (HR-like) and systemic necrotic lesions (Ehrenfeld et al., 2005). Since TMV-U1 and TMV-Cg present similar genome organization and molecular weight, we decided to evaluate if the movement protein of $\mathrm{TMV}-\mathrm{Cg}(\mathrm{MP}-\mathrm{Cg})$ 
could be used by TMV-U1 in order to infect tobacco plants successfully. In the present work, transgenic tobacco plants expressing the MP-Cg were produced and evaluated for movement of a TMV-U1 mutant virus lacking in the MP. The study of two tobamoviruses with different host ranges could be important in the understanding of the basic molecular mechanisms that underlie viral infection.

\section{MATERIALS AND METHODS}

\section{Cloning of $\mathrm{MP}-\mathrm{Cg}$}

The MP-Cg gene was amplified by PCR from the plasmid $\mathrm{pCg} 8$, containing fulllength TMV-Cg cDNA (Yamanaka et al., 1998, Arce-Johnson et al., 2003). Primers used were ClaI-MPCg (5' TTTTGATCGATTGAGTCAATAATGTCT TAC-3') with a ClaI restriction site (underlined) and KpnI-MPCg (5'-CAACGC GGTACCGCACTGGTTAAGCATC-3'), including a KpnI restriction site (underlined). The amplification product was digested with ClaI and $\mathrm{KpnI}$ and cloned between the corresponding sites of digested pMON-316 vector to obtain the pMON316-MP-Cg plasmid. The vector contains the npt II gene as a selection marker, which confers kanamycin resistance. The MP-Cg gene is under the control of the CaMV 35S promoter and the transcriptional terminator of the nopaline synthase gene of Agrobacterium tumefaciens.

\section{Production of transgenic plants}

We produced transgenic Nicotiana tabacum plants of two genotypes: Xanthi NN (containing the tobamovirus resistance gene $\mathrm{N}$ ) and Xanthi $\mathrm{nn}$ (sensitive to tobamovirus), using A. tumefaciens GV3111 carrying pMON-316-MP-Cg. Leaf discs were transformed following the method of Horsch (1985). Co-cultures were maintained at $22^{\circ} \mathrm{C}$ for $24 \mathrm{~h}$ in medium with $0.2 \mathrm{mg} / \mathrm{L} \alpha$-naphthaleneacetic acid (NAA) and $1 \mathrm{mg} / \mathrm{L}$ benzyladenine (BA), and then selected with $150 \mathrm{mg} / \mathrm{L}$ kanamycin. Induced shoots were transferred to a medium with no hormones but containing kanamycin instead, allowing root induction. Plantlets were transferred to a greenhouse.

\section{Analysis of transgenic plants}

The expression of the npt II marker gene was evaluated in kanamycin-resistant plants by an enzyme-linked immunosorbent assay (ELISA), using the commercial system Patho Screen-NPTII (AGDIA, USA), according to the manufacturer's instructions. MP-Cg gene presence was evaluated by PCR using the same set of PCR primers used to amplify the MP-Cg gene from viral cDNA. Plant genomic DNA was isolated following the Straus and Ausubel (1990) method. Taq polymerase (Invitrogen, Carlsbad, CA) amplification reactions were performed in a volume of $50 \mu \mathrm{L}$ using the following conditions: $3 \mathrm{~min}$ at $95^{\circ} \mathrm{C}, 30$ cycles of denaturation at $94^{\circ} \mathrm{C}$ for $1 \mathrm{~min}$, annealing at $56^{\circ} \mathrm{C}$ for $45 \mathrm{~s}$, extension at $72^{\circ} \mathrm{C}$ for $2 \mathrm{~min}$, and a final extension for $7 \mathrm{~min}$ at $72^{\circ} \mathrm{C}$.

Expression of MP-Cg transcripts was evaluated by RT-PCR. Total RNA was isolated from MP-Cg-positive plants, according to Logemann et al. (1987). Firststrand cDNA was synthesized using an oligo-dT $\mathrm{d}_{12-18}$ as primer and SuperScript II enzyme (Invitrogen, Carlsbad, CA). The amplification reaction conditions were the same as described for PCR but using $100 \mathrm{ng}$ of cDNA as template. In both cases, the size of the expected amplified band for MP$\mathrm{Cg}$ is $839 \mathrm{pb}$.

\section{Viral movement complementation}

The mutant TMV-U1 1 MP was used to complement the function of MP in transgenic lines. The mutant virus was purified from transgenic MP-U1 plant line 277. These tobacco plants have MP-U1 under transcriptional control of CaMV-35S promoter and express MP-U1 constitutively in all tissues (Deom et al., 1987) and thus were used for the maintenance of TMV$\mathrm{U} 1 \Delta \mathrm{MP}$ and also as a positive control of complementation. For virus purification, a previously described method that includes ultracentrifugation of extracts from infected plants (Padgett and Beachy, 1993) was used. 
Six-week-old plants were inoculated mechanically with $1 \mu \mathrm{g}$ of mutant virus in 20$\mathrm{mM}$ phosphate buffer. In the Xanthi nnsensitive transgenic MP-Cg lines, the movement of TMV-U1 $1 \mathrm{MP}$ was evaluated by the presence of the coat protein using ELISA and Western blot assays. Leaf disks were collected from inoculated and apical tissues at $0,4,8,12$, and 16 days post-inoculation (dpi) and stored at $-20^{\circ} \mathrm{C}$. Protein extraction for ELISA assay was performed in buffer with $1.59 \mathrm{~g} / \mathrm{L}$ sodium carbonate, $2.93 \mathrm{~g} / \mathrm{L}$ sodium bicarbonate, $0.2 \mathrm{~g} / \mathrm{L}$ sodium azide, and $20 \mathrm{~g} / \mathrm{L}$ $\mathrm{PVP}_{24-40}$, adjusted at $\mathrm{pH}$ 9.6. For Western blot analysis, protein extraction was performed in buffer containing $125 \mathrm{mM}$ Tris- $\mathrm{HCl} \mathrm{pH}$ 6.8, $0.1 \%$ SDS, and $20 \%$ glycerol. For each transgenic line, complementation experiments were done by triplicate.

\section{RESULTS}

\section{MP-Cg transgenic lines}

Thirteen Xanthi NN plants and ten Xanthi nn plants showed kanamycin resistance and expressed the npt II gene, as was confirmed by the ELISA test. For each line, the T3 generation was obtained by self-pollination of transgenic plants and was used for further analysis. Transgenic MP-Cg plants are listed in Table 1, along with two MP-U1 transgenic control lines: 2005-Xanthi NN
(Deom et al., 1991) and 277-Xanthi nn (Deom et al., 1987). Lines 2005 and 277 are tobamovirus-resistant and -sensitive plants that constitutively express MP-U1 and were used as positive control because these plants are able to complement movement function of TMV-U1 $\Delta M P$ virus. The MP$\mathrm{Cg}$ presence was evaluated by PCR analysis in transgenic tobacco plants (Figure 1A). The expected amplified fragment of $839 \mathrm{bp}$ was found in six Xanthi NN and seven Xanthi nn lines, while the MP-Cg transcript expression was detected by RT-PCR in five Xanthi NN and in six Xanthi nn transgenic plants (Figure 1B). These results confirm that these transgenic lines express $\mathrm{MP}-\mathrm{Cg}$ gene. Unexpectedly, line 5.6 did not show expression of MP-Cg gene by RT-PCR, although it was positive by PCR. The insertion site of the transgene in the plant genome probably prevents its expression. This line was discarded for further analysis.

Complementation of viral movement function by transgenic plants

Since viral infection requires the presence of a MP, the mutant virus TMV-U1 $\Delta \mathrm{MP}$ is not able to spread systemically in wild-type tobacco. For this reason, this mutant virus was maintained in transgenic tobacco plants 277, which express MP-U1 protein and allow systemic spread of this virus (Deom et al., 1987).

All transgenic lines express viral movement proteins under transcriptional control of CaMV 35S promoter and represent independent transformation events. Lines A1, A3, B, B2, B5, E and 3.1, 3.2, 3.3, 4.2, 5.4, 5.6, 5.7 correspond to MP-Cg-expressing tobacco plants. Lines 2005 and 277 express MP-U1 in a background Nicotiana tabacum Xanthi NN or Xanthi nn, respectively, and were used as a positive control of complementation for all

experiments. Tobacco Xanthi NN and Xanthi nn correspond to genotypes resistant and sensitive to tobamovirus, respectively.

\begin{tabular}{lccc}
\hline Plant Lines & \multicolumn{1}{c}{ Genotype } & Transgene & Reference \\
\hline & & & This work \\
A1, A3, B, B2, B5, E & N.tabacum cv Xanthi NN & TMV-Cg-MP & This work \\
$3.1,3.2,3.3,4.2,5.4,5.6,5.7$ & N.tabacum cv Xanthi nn & TMV-Cg-MP & Deom, Virology 180, 251-256, 1991 \\
2005 & N.tabacum cv Xanthi NN & TMV-U1-MP & Deom, Sciencie 237, 389-394, 1987 \\
277 & N.tabacum cv Xanthi nn & TMV-U1-MP & \\
\hline
\end{tabular}


A

A Tobacco xanthi NN-MPCg

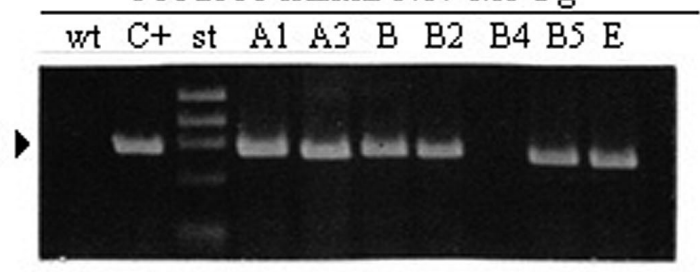

B

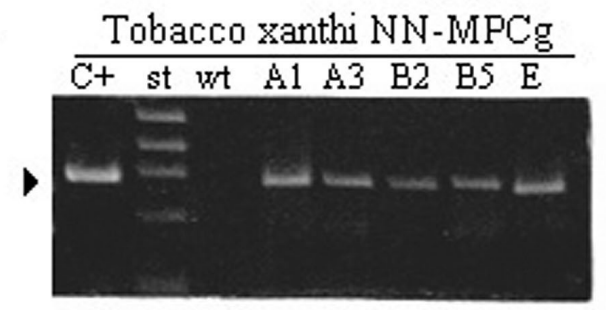

Tobacco xanthi nn-MPCg
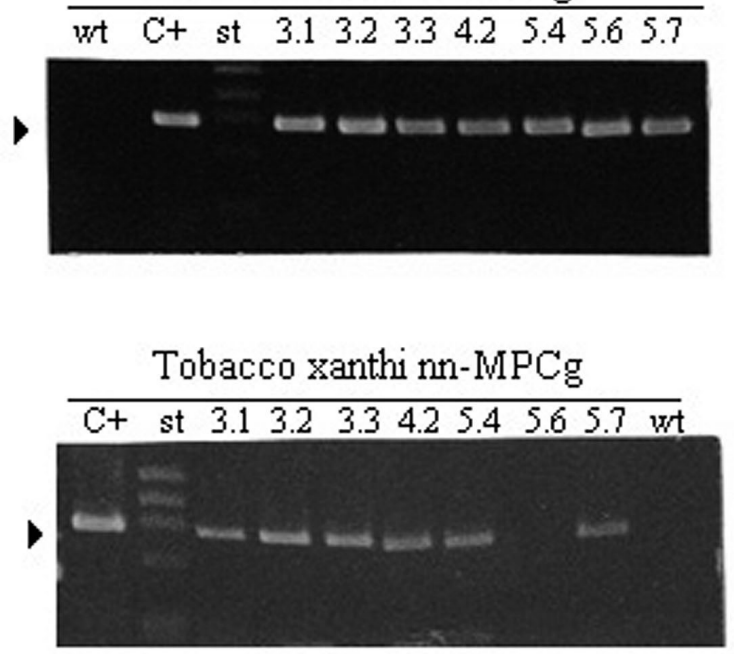

Figure 1: Molecular characterization of transgenic lines coding MP-Cg. Arrowheads denote the expected fragment of 839 bp. Wt, wild-type Xanthi NN or Xanthi nn tobacco plants. St, molecular weight marker $\phi X 174 /$ Hae III. (A) Detection of MP-Cg gene in transgenic plants by PCR. C+, positive control corresponding to the amplification of MP-Cg gene from cDNA of TMV-Cg clone PCg8. (B) Detection MP-Cg transcript by RT-PCR.

The functionality of the MP-Cg was evaluated on both transgenic genotypes (Xanthi NN and nn), which were inoculated with the local trafficking-deficient mutant TMV-U1 1 MP. Figure 2 shows the infection in transgenic-resistant Xanthi NN lines with mutant virus. This genotype carries the resistance gene $\mathrm{N}$ and develops necrotic lesions as a result of a hypersensitive response when they are infected with tobamoviruses. The MP-Cg transgenicresistant lines A1 and A3 developed local necrotic lesions at $3 \mathrm{dpi}$ with an average size of $2 \mathrm{~mm}$. These lesions were similar in shape and size to the lesions obtained in the control line 2005, which express MP-U1 and facilitate cell-to-cell movement of the mutant virus TMV-U1 $1 \mathrm{MP}$ (Deom et al., 1991). In line E plants, we obtained lesions of $3 \mathrm{~mm}$ on average, and lines B, B2, and B5 did not developed lesions. Wild-type plants Xanthi NN did not develop local lesions after inoculation with mutant virus. Since viral cell-to-cell movement is necessary for the local lesion development by the plant (Deom et al., 1987), these results show that $\mathrm{MP}-\mathrm{Cg}$ expressed in resistant lines (A1, A3, and E) complemented the movement function of the mutant virus.

In the case of transgenic-sensitive Xanthi nn lines, both local and systemic movement of TMV-U1 $\Delta \mathrm{MP}$ were evaluated by the presence of the coat protein on inoculated and apical leaves, respectively. All plant lines showed movement complementation to some extent. Figure 3 shows local and systemic movement complementation of the mutant in four sensitive transgenic plants. Lines 3.1 and 4.3 had the best behavior, allowing mutant virus movement as efficiently as in positive control line 277. An example of viral coat protein accumulation is shown in Figure 4 for line 3.1. This transgenic line accumulates mutant virus in local and systemic tissues at 7 and $14 \mathrm{dpi}$, as occurs in 277 control line, and as we expected, TMV-U1 $\Delta$ MP was not able to spread in wild-type sensitive Xanthi nn plants. The presence of the CP-U1 in apical and inoculated leaves by Western blot and ELISA analysis clearly shows that MP-Cg expressed in sensitive plants complements movement function of TMV-U1 $\mathrm{TMP}$, as also occurred in resistant lines. 
A

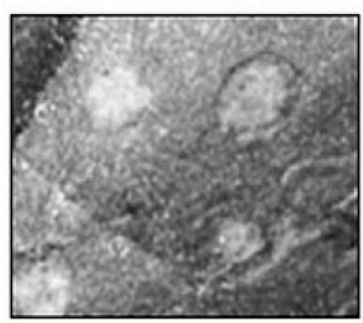

B

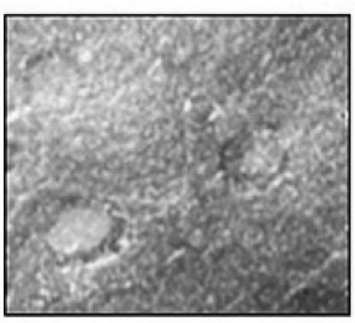

\begin{tabular}{cc}
\hline Plant line & Lesion diameter $(\mathrm{mm})$ \\
\hline A1, A3, & 2 \\
E & 3 \\
B, B2, B5 & - \\
2005 & 2 \\
xanthi NN & - \\
\hline
\end{tabular}

Figure 2: Complementation of mutant virus movement function by MP-Cg expressed in resistant tobacco plants. Three plants of each transgenic line, as well as MP-U1-expressing control line 2005, and wild-type Xanthi NN plants were inoculated with TMV-U1 $\Delta$ MP in medium leaves. A) Three days post-inoculation, local lesions characteristic of the hypersensitive response were evident in MP-Cg-expressing line A3 (left) and were similar to the response observed in control line 2005 (right). B) Table shows the lesion size obtained for all MP-Cg-expressing lines evaluated, in addition to line 2005 and wild-type plant after the inoculation with TMV- $\Delta$ MP.
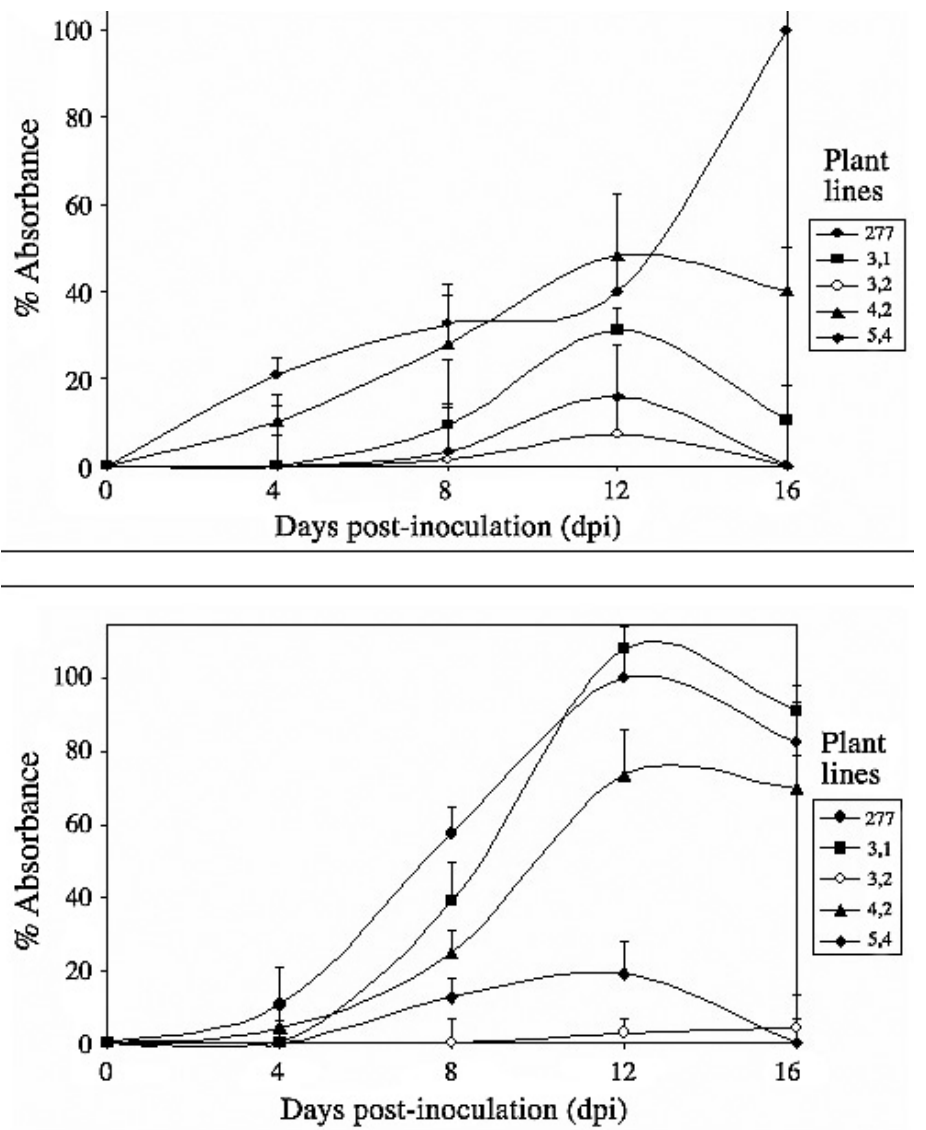

Figure 3: Heterologous complementation of mutant virus movement function by MP-Cg Xanthi nn transgenic lines. Three plants of each line were inoculated with TMV-U1 $\Delta M P$ in medium leaves, and samples were taken at 4, 8, 12, and 16 dpi. ELISA assays against TMV-U1 coat protein were performed on extracts from inoculated $\mathbf{A}$ ) and systemic leaves $\mathbf{B}$ ) to illustrate kinetics of the viral accumulation resulting from local and systemic spread, respectively. For each transgenic line, absorbance values obtained are expressed as a percent relative to viral accumulation in 277 control line. Means of the three replicates and corresponding standard deviations are shown. 
Xanthi nn

Control line 277

MP-Cg line 3.1

\begin{tabular}{|c|c|c|c|c|c|c|c|c|c|c|}
\hline \multicolumn{2}{|c|}{$7 \mathrm{dpi}$} & \multicolumn{2}{|c|}{$14 \mathrm{dpi}$} & \multicolumn{2}{|c|}{$7 \mathrm{dpi}$} & \multicolumn{2}{|c|}{$14 \mathrm{dpi}$} & \multicolumn{2}{|c|}{$7 \mathrm{dpi}$} & $14 \mathrm{dpi}$ \\
\hline L & $\mathrm{S}$ & L & S & L & $\mathrm{S}$ & L & $\mathrm{S}$ & L & $\mathrm{S}$ & L $\quad S$ \\
\hline
\end{tabular}

Figure 4: Accumulation of TMV-U1 $1 \mathrm{MP}$ coat protein in transgenic line 3.1. Western blot shows a similar behavior of mutant virus during homologous complementation in control line 277 (expressing MP-U1) and during heterologous complementation in transgenic line 3.1 (expressing MP-Cg). Local (L) and systemic (S) leaves were evaluated at 7 and 14 days post-inoculation (dpi). A non-transgenic plant Xanthi nn was used as negative control, and no viral coat protein was observed in this case. A representative result from three experiments is shown.

\section{DISCUSSION}

The ability of TMV-U1 $\Delta$ MP to use MP-Cg efficiently was evaluated in two genotypes of MP-Cg-expressing plants: resistant and sensitive to tobamoviruses. It is well know that resistant tobacco plants (genotype NN) develop local necrotic lesions that are the result of a hypersensitive response at the inoculated leaves, when they are infected with tobamoviruses. Although the hypersensitive response restricts the virus to the inoculated leaves, avoiding a systemic infection, it requires cell-to-cell movement of the pathogen. Thus, if TMV$\mathrm{U} 1 \Delta \mathrm{MP}$ is able to spread locally in MP-Cg transgenic lines, a development of a hypersensitive response should be observed. Some transgenic MP-Cg lines restore local movement of mutant virus at a different level, as was observed by the appearance of local lesions. At the same time, average lesion size varied between lines. Local lesion size reflects the replication and movement efficiency of a virus, and in our case, size differences in TMV-U1 $\Delta$ MP-induced lesions could be due to movement protein availability in the plant. Large lesion sizes are related to a less-effective hypersensitive reaction that could be explained by lower MP availability for virus movement.

MP-Cg expressed in sensitive plants also complements the movement function of
TMV-U1 $\Delta \mathrm{MP}$, allowing local and systemic viral spread and the establishment of a successful infection. Interestingly, infection caused by TMV-U1 $1 \mathrm{MP}$ in sensitive MPCg-expressing plants produces mosaic-like symptoms similar to TMV-U1, differing from the HR-like response caused by TMV$\mathrm{Cg}$. This fact discards the role of MP-Cg as a determinant of this necrotic phenotype. All these results suggest that the movement-defective TMV-U1 $1 \mathrm{MP}$ uses the MP-Cg, which belongs to a different tobamovirus subgroup, to transfer its genome from cell to cell.

Different levels of complementation were observed in both resistant and sensitive transgenic lines. Transgenic lines that were not able to restore the movement function of mutant virus, possibly expressed null or low levels of $\mathrm{MP}-\mathrm{Cg}$ protein. According to this assumption, those lines that allowed the spread of mutant virus probably produced enough amount of movement protein. Variability in expression levels of transgenic protein could be due to the site of gene insertion, number of transgene copies present in the genome or other characteristics of individual lines. It was demonstrated that efficiency of TMV$\mathrm{U} 1 \Delta \mathrm{MP}$ to establish an infection in tobacco lines 277 or 2005 reaches a maximum when plants produce about $30 \%$ of MP present in wild-type plants infected with TMV-U1 (Arce-Johnson et al., 1995). It is probable 
that complementation with mutant virus only occurs when transgenic lines synthesize enough movement protein to reach this threshold level. Moreover, considering that TMV-U1 $\triangle \mathrm{MP}$ has to use a different MP than its own, this requirement could be higher. In those plants with movement complementation, the amount of MP-Cg in tissues was sufficient to allow virus function.

MPs of diverse viruses have a common feature: the capacity to increase the sizeexclusion limit of the PDs. For example, tobacco transgenic plants expressing the MP-U1 showed an increased size-exclusion limit in their PDs (Wolf et al., 1989), and even though PDs trafficking is a highly controlled process for differentiation purposes (Ruiz-Medrano et al., 2004; Xoconostle-Cazares, 1999), these MPexpressing plants did not present any apparent defect at the phenotypic level. Here, we reported the production of tobacco transgenic plants expressing the MP of the crucifer-infecting TMV-Cg under the control of the CaMV $35 \mathrm{~S}$ promoter, and these plants did not show any defect in growth or seed production.

An alignment between protein sequences of MP-U1 and MP-Cg showed an identity of $36 \%$ distributed along the overall sequences (Fig. 5A). Despite the low identity observed at the amino acidic level, an analysis of amino acid distribution among these proteins allows us to establish similar patterns of hydrophobic and hydrophilic regions (Fig. 5B). Interestingly, the amino terminal region is the most conserved between both proteins at sequence level ( $44 \%$ of identity), but the similarities in the ordering of hydrophobic and hydrophilic regions are concentrated in the carboxylic region of the proteins where identity only reaches $21 \%$. Numerous functions have been related to this region, like binding to nucleic acids, the presence of phosphorylation sites, increase of the size-exclusion limit of PDs, and interaction with some host proteins (Brill et al., 2000; Citovsky, 1999; Chen et al., 2000; Waigmann et al., 1994). All these processes are important for the biological role of MPs and probably a conserved structure, especially in the carboxylic region, could explain the interchangeability between viral movement proteins.

Trans-complementation of cell-to-cell movement between plant RNA viruses has been demonstrated for related viruses as well as for viruses belonging to different taxonomic groups (Atabekov et al., 1999; Briddon and Markham et al., 2001; Deom et al., 1991; Kaplan et al., 1995; Sanz et al., 2000; Tamai et al., 2003). Different conservation levels between movement proteins, varying from about $10 \%$ to $50 \%$, have allowed complementation of several trafficking deficient-mutant viruses in transgenic plants expressing MPs, supporting the importance of the secondary structure in their function (Deom et al., 1994; Cooper et al., 1996; GiesmanCookmeyer et al., 1995; Nejidat et al., 1991). While some MPs are functionally interchangeable with other MPs, comparisons of MP sequences have not been helpful in determining how these proteins function. In this sense, the variability observed in complementation experiments reported so far reveals that cellular factors also can be involved in virus movement.

The study of viral MPs has allowed a better understanding of local trafficking in plants. It has been revealed that the MP is the viral paralog of cellular proteins such as KNOTTED1 (Lucas et al., 1995), CmPP16 (Xoconostle-Cazares et al., 1999), and CmPP36 (Xoconostle-Cazares et al., 2000), which are involved in the transport of large RNA molecules through PDs. Even though there is low conservation at the amino acidic level in between these diverse proteins, they all function to transport RNA molecules of diverse origin through PDs. In addition, many of these proteins can be interchanged between viruses showing a high degree of functional conservation during evolution. Even through the movement proteins of TMV-U1 and TMV$\mathrm{Cg}$ are dissimilar, their distribution of hydrophobic and hydrophilic regions suggests conservation in protein structure that could explain the conservation of function between these viral movement proteins. 
A

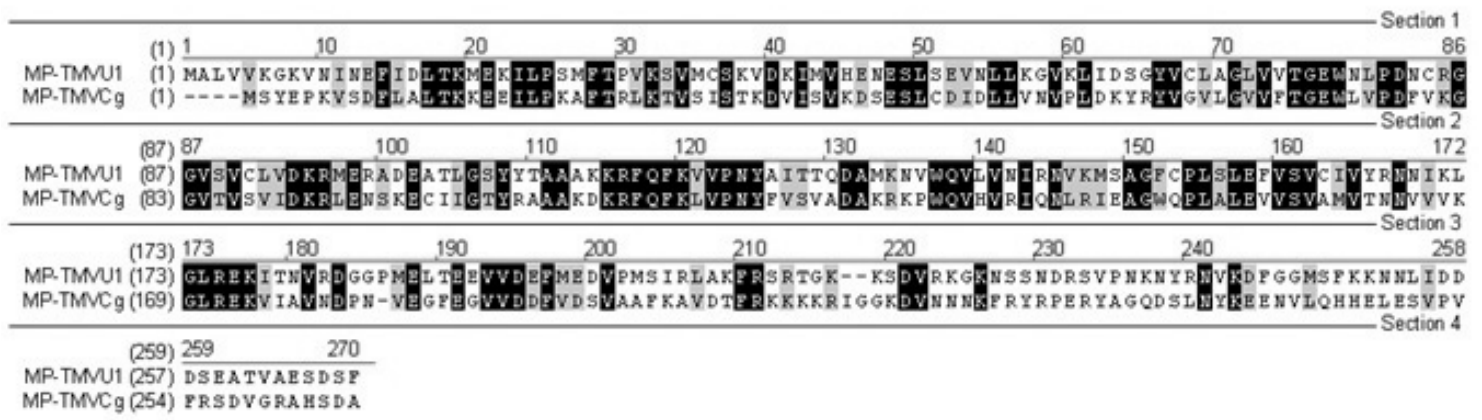
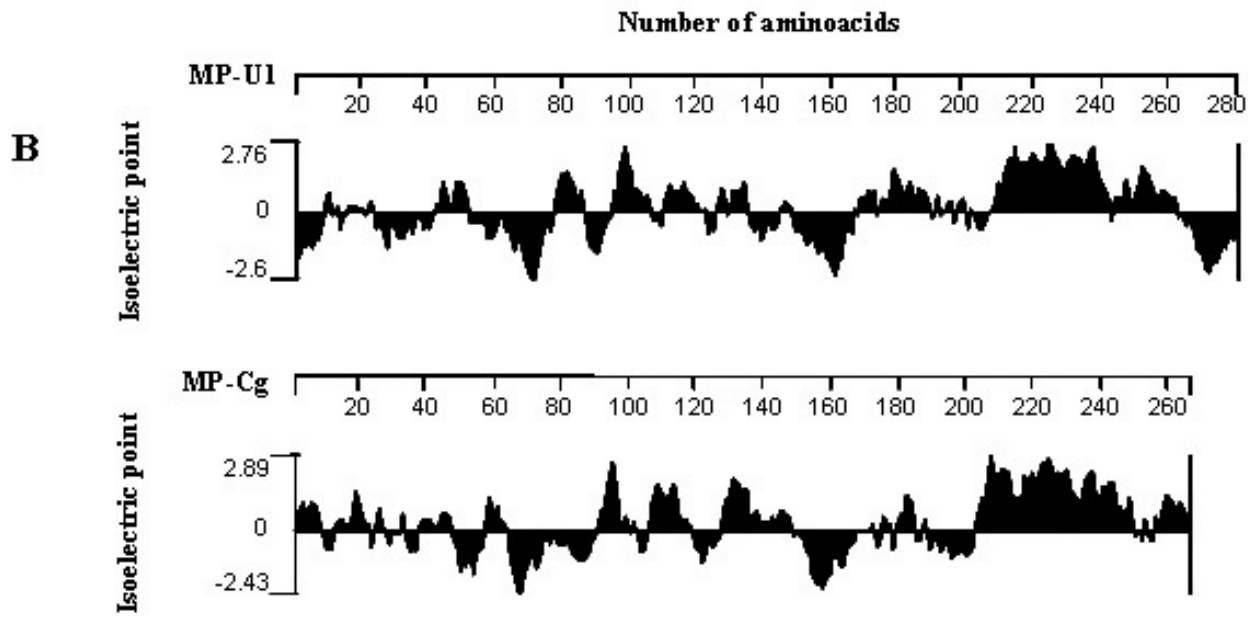

Figure 5: Comparison between movement proteins of TMV-U1 and TMV-Cg. A) Sequence alignment of movement proteins MP-U1 and MP-Cg. The alignment was performed using the Clustal W algorithm-based AlignX ${ }^{\circledR}$ module, available from Vector NTI Suite 8.0 software (Invitrogen, USA). Gray and black boxes represent blocks of similar and identical amino acids, respectively. B) Hydrophobic plots of MP-U1 and MP-Cg. Hydrophobic regions are represented by positive values of isoelectric points and thus fall over the central line. Hydrophilic regions have negative isoelectric point and are located below the central line. Plots were made with the DNAStart program. Analysis were done with the amino acidic sequences of MP-U1 (Accession number: P03583) and MP-Cg (Accession number: NP_740758).

\section{ACKNOWLEDGEMENTS}

This research was supported by Fondecyt grant $\mathrm{N}^{\mathrm{o}} 1040789$ to PAJ.

\section{REFERENCES}

ARCE-JOHNSON P, KAHN TW, RIVERABUSTAMANTE R, BEACHY RN (1995) The amount of movement protein produced in transgenic plants influences the establishment, local movement, and systemic spread of infection by movement proteindeficient tobacco mosaic virus. Mol Plant-Microbe Interact 8: 415-423

ARCE-JOHNSON P, MEDINA C, PADGETT H,
HUANCA W, ESPINOZA C (2003) Analysis of local and systemic spread of the crucifer-infecting TMV-Cg virus in tobacco and several Arabidopsis thaliana ecotypes. Functional Plant Biology 30: 401-408

ATABEKOV JG, MALYSHENKO SI, MOROZOV YUS, TALIANSKY ME, SOLOVYEV AG, AGRANOVSKY AA, SHAPKA NA (1999) Identification and study of tobacco mosaic virus movement function by complementation tests. Philos Trans R Soc Lond B Biol Sci 354(1383): 629-35

ATABEKOV JG, TALIANSKY ME (1990) Expression of a plant virus-coded transport function by different viral genomes. Adv Virus Res 38: 201-48

BEACHY RN, ZAITLIN M (1977) Characterization and in vitro translation of the RNAs from less-than-full-length virus related nucleoprotein rods present in tobacco mosaic virus preparations. Virology 81: 160-169

BRIDDON RW, MARKHAM PG (2001) Complementation of bipartite begomovirus movement functions by 
topocuviruses and curtoviruses. Arch Virol 146: 18119

BRILL L, NUNN RS, KAHN TW, YEAGER M, BEACHY RN (2000) Recombinant tobacco mosaic virus movement protein is an RNA-binding, $\alpha$-helical membrane protein. Proc Natl Acad Sci USA, 97(13): 7112-7117

CARRINGTON J, KASSCHAU K, MAHAJAN S, SCHAAD M (1996) Cell-to-cell and long-distance transport of viruses in plants. The Plant Cell 8: 16691681

CHEN M, SHENG J, HIND G, HANDA A, CITOVSKY V (2000) Interaction between the tobacco mosaic virus movement protein and host cell pectin methylesterases is required for viral cell-to-cell movement. EMBO J 19(5): 913-920

CITOVSKY V, KNORR D, SCHUSTER G, ZAMBRYSKI $\mathrm{P}$ (1990) The P30 movement protein of tobacco mosaic virus is a single-strand nucleic acid binding protein. Cell 60: 637-647

CITOVSKY V, WONG ML, SHAW A, PRASAD BV, ZAMBRYSKI P (1992) Visualization and characterization of tobacco mosaic virus movement protein binding to single-stranded nucleic acids. Plant Cell 4: 397-411

CITOVSKY V, MCLEAN BG, ZUPAN JR, ZAMBRYSKI $P$ (1993) Phosphorylation of tobacco mosaic virus cellto-cell movement protein by a developmentally regulated plant cell wall-associated protein kinase. Genes Dev 7: 904-10

CITOVSKY V (1999) Tobacco mosaic virus: A pioneer of cell-to-cell movement. Phil Trans R Soc Lond B 354: 637-643

COOPER B, SCHWITZ I, RAO ALN, BEACHY RN, DODDS JA (1996) Cell-to-cell transport of movementdefective cucumber mosaic and tobacco mosaic viruses in transgenic plants expressing heterologous movement protein genes. Virology 216: 208-213

DEOM CM, OLIVER MJ, BEACHY RN (1987) The 30kilodalton gene product of tobacco mosaic virus potentiates virus movement. Science 237: 384-389

DEOM CM, WOLF S, HOLT CA, LUCAS WJ, BEACHY RN (1991) Altered function of the tobacco mosaic virus movement protein in a hypersensitive host. Virology 180: 251-256

DEOM CM, HE XZ, BEACHY RN, WEISSINGER AK (1994) Influence of heterologous tobamovirus movement protein and chimeric movement protein genes on cell-to-cell and long-distance movement. Virology 205: 198-209

EHRENFELD N, CAÑON P, STANGE C, MEDINA C, ARCE-JOHNSON P (2005) Tobamovirus coat protein $\mathrm{CPCg}$ induces an HR-like response in sensitive tobacco plants. Molecules and Cells 19: 1-9

GHOSHROY S, LARTEY R, SHENG J, CITOVSKY V (1997) Transport of proteins and nucleic acids through plasmodesmata. Annu Rev Plant Physiol Plant Mol Biol 48: 27-50

GIESMAN-COOKMEYER D, SILVER S, VAEWHONGS AA, LOMMEL SA, DEOM CM (1995) Tobamovirus and dianthovirus movement proteins are functionally homologous. Virology 213: 38-45

GOREGAOKER SP, CULVER JN (2003) Oligomerization and activity of the helicase domain of the Tobacco Mosaic Virus 126- and 183- kilodalton replicase proteins. Journal of Virology 77: 3549-3556

HACKER DL, FOWLER BC (2000) Complementation of the host range restriction of southern cowpea mosaic virus in bean by southern bean mosaic virus. Virology 266: $140-149$
HALEY A, HUNTER T, KIBERSTIS P, ZIMMERN D (1995) Multiple serine phosphorylation sites on the 30 $\mathrm{kDa}$ TMV cell-to-cell movement protein synthesized in tobacco protoplasts. Plant J 8: 715-24

HAYWOOD V, KRAGLER F, LUCAS WJ (2002). Plasmodesmata. Pathways for protein and ribonucleoprotein signaling. The Plant Cell 14: s303s325

HEINLEIN M, EPEL BL, PADGETT HS, BEACHY RN. (1995) Interaction of tobamovirus movement proteins with the plant cytoskeleton. Science 270 (5244): 1983-5

HORSCH RB, FRY JE, HOFFMAN NL, EICHUOLTZ DR, ROGERS SG, FRALEY RT (1985) A simple and general method for transforming genes into plants. Science 227: 1229-1231

KAPLAN IB, SHINTAKU MH, LI Q, ZHANG L, MARSH LE, PALUKAITIS P (1995) Complementation of virus movement in transgenic tobacco expressing the cucumber mosaic virus 3a gene. Virology 209(1): 18899

KARGER EM, FROLOVA OY, FEDOROVA NV, BARATOVA LA, OVCHINNIKOVA TV, SUSI P, MAKI K, RONNSTRAND L, DOROKHOV YL, ATABEKOV JG (2003) Dysfunctionality of a tobacco mosaic virus movement protein mutant mimiking threonine 104 phosphorylation. J Gen Virol 84: 727732

KAWAKAMI S, WATANABE Y, BEACHY RN (2004) Tobacco mosaic virus infection spreads cell-to cell as intact replication complexes. Proc Natl Acad Sci USA 101: 6291-6296

LEE JY, LUCAS W (2001) Phosphorylation of viral movement proteins-regulation of cell-to-cell trafficking. TRENDS in Microbiology 9: 5-8

LOGEMANN J, SCHELL J, WILLMITZER L (1987) Improved method for the isolation of RNA from plant tissue. Anal Biochem 163: 16-20

LEISNER SM, HOWELL SH (1993) Long distance movement of viruses in plants. Trends Microbiol 1: 314-317

LUCAS WJ, BOUCHE-PILLON S, JACKSON DP, NGUYEN L, BAKER L, DING B, HAKE S (1995) Selective trafficking of KNOTTED1 homeodomain protein and its mRNA through plasmodesmata. Science 270 (5244): 1980-3

MOROZOV SY, FEDORKIN ON, JUTTNER G, SCHIEMANN J, BAULCOMBE DC, ATABEKOV JG (1997) Complementation of a potato virus X mutant mediated by bombardment of plant tissues with cloned viral movement protein genes. J Gen Virol 78: 2077-83

NEJIDAT A, CELLIER F, HOLT CA, GAFNY R, EGGENBERGER AL, BEACHY RN (1991) Transfer of the movement protein gene between two tobamoviruses: Influence on local lesion development. Virology 180: 318-326

PADGETT HS, BEACHY RN (1993) Analysis of a tobacco mosaic virus strain capable of overcoming $\mathrm{N}$ genemediated resistence. Plant Cell 5: 577-586

PEREDA S, EHRENFELD N, MEDINA C, DELGADO J, ARCE-JOHNSON P (2000) Comparative analysis of TMV-Cg and TMV-U1 detection methods in infected Arabidopsis thaliana. J Virol Methods 90: 135-42

RUIZ-MEDRANO R, XONOCOSTLE-CAZARES B, KRAGLER F (2004) The plasmodesmatal transport pathway for homeotic proteins, silencing signals and virases. Curr Opin Plant Biol 7: 641-650

SANZ AI, SERRA MT, GARCÍA-LUQUE I (2000) Altered local and systemic spread of movement deficient virus in transgenic tobacco plants expressing the cucumber mosaic virus 3a protein. Arch Virol 145: 2387-401 
STRAUS D, AUSUBEL FM (1990) Genomic substraction for cloning DNA corresponding to deletion mutations. Proc Natl Acad Sci USA 87: 1889-1893

TAMAI A, KIBOTA K, NAGANO H, YOSHII M, ISHIKAWA M, MISE K, MESHI T (2003) Cucumovirus- and bromovirus-encoded movement functions potentiate cell-to-cell movement of tobamo and potexviruses. Virology 315: 56-67

WAIGMANN E, LUCAS W, CITOVSKY V, ZAMBRYSKI P (1994) Direct functional assay for tobacco mosaic virus cell-to-cell movement protein and identification of a domain involved in increasing plasmodesmatal permeability. Proc Natl Acad Sci USA 91: 1433-1437

WAIGMANN E, CHEN M, BACHMAIER R, GHOSHROY S, CITOVSKY V (2000) Regulation of plasmodesmatal transport by phosphorylation of tobacco mosaic virus cell-to-cell movement protein. EMBO J 19: 4875-4884

WATANABE Y, OGAWA T, OKADA Y (1992) In vivo phosphorylation of the $30-\mathrm{kDa}$ protein of tobacco mosaic virus. FEBS Lett 313: 181-4

WATANABE Y, EMORI Y, OOSHIKA I, MESHI T, OHNO T, OKADA Y (1984) Synthesis of TMVspecific RNAs and proteins at the early stage of infection in tobacco protoplasts: Transient expression of the $30 \mathrm{~K}$ protein and its RNA. Virology 133: 18-24

WOLF S, DEOM CM, BEACHY RN, LUCAS WJ (1989)

Movement protein of tobacco mosaic virus modifies plasmodesmatal size exclusion limit. Science 246: 377-379

XOCONOSTLE-CAZARES B, XIANG Y, RUIZMEDRANO R, WANG HL, MONZER J, YOO BC, MCFARLAND KC, FRANCESCHI VR, LUCAS WJ (1999) Plant paralog to viral movement protein that potentiates transport of mRNA into the phloem. Science 283 (5398): 94-8

XOCONOSTLE-CAZARES B, RUIZ-MEDRANO R, LUCAS WJ (2000) Proteolytic processing of CmPP36, a protein from the cytochrome $b(5)$ reductase family, is required for entry into the phloem translocation pathway. Plant Journal 24: 735-747

YAMANAKA T, KOMATANI $\mathrm{H}$, MESHI T, NAITO $\mathrm{S}$, ISHIKAWA M, OHNO T (1998) Complete nucleotide sequence of the genomic RNA of tobacco mosaic virus strain Cg. Virus Genes 16: 173-176

ZAMBRYSKI P (2004) Cell-to-cell transport of proteins and fluorescent tracers via plant plasmodesmata during plant development. The Journal of Cell Biology 164: 165-168 